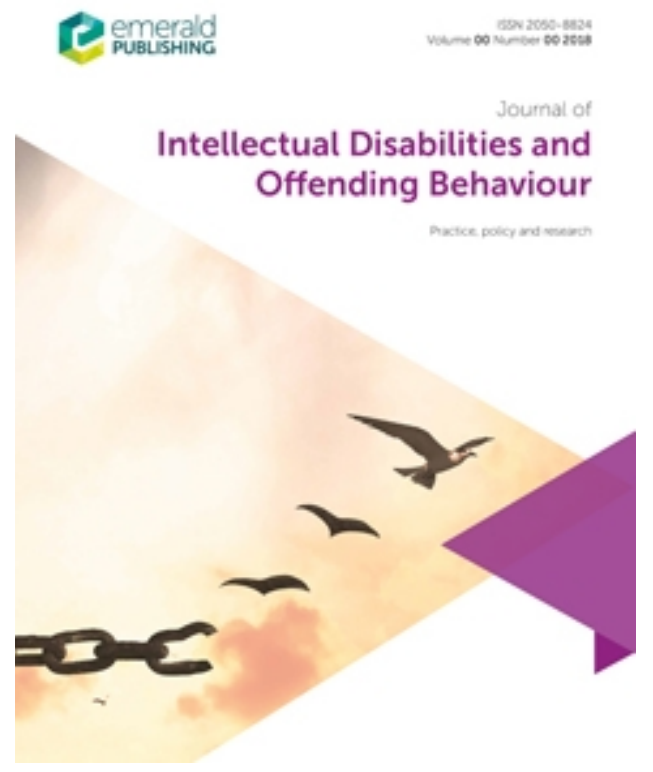

\title{
Autism Spectrum Disorder, Bestiality and Zoophilia: A Systematic PRISMA Review
}

\begin{tabular}{|r|l|}
\hline Journal: & Journal of Intellectual Disabilities and Offending Behavior \\
\hline Manuscript ID & JIDOB-06-2019-0012 \\
\hline Manuscript Type: & Research Paper \\
\hline Keywords: & $\begin{array}{l}\text { Zoophilia, Bestiality, Sexual Behavior, Autism Spectrum Disorder, } \\
\text { Asperger's Syndrome, Bestiosexuality }\end{array}$ \\
\hline \multicolumn{2}{|l}{} \\
\hline
\end{tabular}

\section{SCHOLARONE \\ Manuscripts}


Autism Spectrum Disorder, Bestiality and Zoophilia: A Systematic PRISMA Review 


\begin{abstract}
Purpose: There remains a lack of knowledge surrounding paraphilic or deviant arousal sexual behaviours in individuals with ASD (Kellaher, 2015). The aim of the present systematic review is to explore the literature for any empirical study, case study or discussion/review paper surrounding individuals with ASD and zoophilia or bestiality. Methodology: A systematic PRISMA review was conducted. Findings: This systematic review highlighted only a small number of papers which have looked at zoophilia or bestiality in individuals with ASD. Only one article was identified as being relevant in the present review, three further articles included a description of a case involving someone with ASD who engaged in zoophilia or bestiality and another paper, although not the focus of the study, found one person with Asperger's Disorder who had several paraphilias including olfactophilia, podophilia and zoophilia in a sample of 20 institutionalized, male adolescents and young adults with Autistic Disorder (AD) and borderline/mild mental retardation (MR). All the case studies clearly highlight some of the ASD symptomology that can contribute to engaging in bestiality or zoophilia. Practical Implications: It is important that individuals with ASD have access to appropriate and timely sex education and that parents are supported by healthcare professionals to engage with their children with ASD in such interactions across the autism spectrum irrespective of the parent's expectations. Originality: To the authors knowledge, this is the first review on ASD in relation to bestiality and zoophilia.
\end{abstract}

Keywords: Autism spectrum disorders; ASD; asperger's syndrome; bestiality; zoophilia; zoosexual behaviour; zoophilism; zooerasty; zooerastia; bestiosexuality. 


\section{Introduction}

\section{Zoophilia and Bestiality}

Zoophilia is a paraphilic disorder with intense recurrent sexual fantasies, urges and behaviours involving animals. In the fifth edition of Diagnostic and Statistical Manual (DSM-5) zoophilia is categorised under "other specified paraphilic disorder" in the DSM-5. The DSM-5 classifies paraphilia as "any intense and persistent sexual interest other than sexual interest in genital stimulation or preparatory fondling with phenotypically normal, physically mature, consenting human partners" (APA, 2013, pp. 685). The DSM-5 makes a distinction between a paraphilia and a paraphilic disorder. It states that a paraphilic disorder "is a paraphilia that is currently causing distress or impairment to the individual or a paraphilia whose satisfaction has entailed personal harm, or risk of harm, to others" (APA, 2013, pp. 685-686). Additionally, zoophilia is classified as disordered if this behaviour is egodystonic and harmful to oneself or others. In the DSM-5, there are eight specific paraphilias detailed, namely, voyeuristic, exhibitionistic, frotteuristic, sexual masochism, sexual sadism, pedophilic, fetishistic and transvestic.

Two categories were added in the DSM-5. These were "other specified paraphilic disorder" (this is replacing paraphilia not otherwise specified) and unspecified paraphilic disorder. These are used when the assessor makes the decision to describe just the diagnostic class. 'Other specified paraphilic disorder' includes, for instance, zoophilia (animals), scatalogia (obscene phone calls), necrophilia (corpses), coprophilia (faeces), klismaphilia (enemas), urophilia (urine) (APA, 2013, pp. 685, 705). Shaffer and Penn (2006) also describe a variety of zoophilia types in their paper. For instance, necrobestialism (arousal from having sex with dead animals); avisodomy (breaking the neck of a bird while penetrating it for sex); anolingus (arousal from licking lizards); phthiriophilia (attraction to lice) and musophilia (arousal from mice). A paraphilic disorder involving animals can be diagnosed under the "other specified paraphilic disorder" category (Holoyda, 2017). Frequently the behavior of sexual contact with the animal(s) occurs in the individuals place of residence or on the farm or stable which affords the individual some degree of privacy, reducing the risk of being reported. The animals which are found to be most commonly used for sex are dogs and horses (Beetz, 2004). In the literature there have been descriptions of over 100 unique paraphilias (Federoff, 2010). The revisions to the DSM-5 (APA, 2013) now makes it possible for an individual to engage in consensual atypical sexual behaviour without it being considered to be a mental disorder. The prevalence in the general population is unknown and is believed to be rare (Holoyda, \& Newman, 2014). 
Bestiality is a term which is used to describe any sexual act which occurs between a human and an animal. Saying that someone engages in bestiality is different to giving a diagnosis of zoophilia. It also fails to explain why someone engage in sexual intercourse with an animal. As explained by Holoyda and Newman (2016), there are a number of different motivations for engaging in sexual intercourse with animals (Holoyda, Sorrentino, Friedman, \& Allgire, 2018). Studies investigating bestiality are limited to specific subgroups such as forensic samples or self-identified zoophiles. It is not fully understood what the prevalence of bestiality is in the general population (Holoyda, Sorrentino, Friedman, \& Allgire, 2018). As discussed by Beetz (2004), Miletski (2002) and Beetz (2002) highlighted the distinction between zoophilia and bestiality. Zoophilia refers to an emotional attachment to animals which is associated with a preference for having animals as sexual partners or that includes a sexual attraction. Bestiality is a term which is used to describe any sexual contact of humans to animals or physical contacts to animals that result in sexual excitement for the human who is engaged in these acts. Crucially, these types of relations between a human and an animal may occur in combination and there is nothing to suggest that they should be treated as totally distinct categories (Miletski, 2002) (Beetz, 2004).

\section{Issues with the diagnostic criteria}

Beech and colleagues (2016) highlight the significant controversy exists surrounding what a paraphilia actually is and when an unusual sexual interest becomes a mental disorder (Moser, 2009). There is a lack of agreement regarding what is "normal" sexual behaviour. As a result, there exists no useful boundary to consider when making decisions regarding what denotes a sexual mental disorder (e.g., Frances \& First, 2011). Indeed, the APA had not offered a definition of normal sexual behavior, in contrast with paraphilic interests until the publication of the DMS-5 (Beech, Miner, \& Thornton, 2016). Moreover, due to the 'malleability' of sexual norms across time and cultures, it is difficult to define the concept of "deviant" sexual behaviour in any absolute way (McManus et al., 2013). The revisions to the DSM-5 aimed to partly address this issue by including 'disorder' after every paraphilia diagnosis. This enables people to engage in (some) atypical sexual behaviours without it being labelled a mental disorder. In the DSM a disorder is classified as a "behavior that causes mental distress to a person or makes the person a serious threat to the psychological and physical wellbeing of other individuals" (http://www.dsm5.org/Documents/Paraphilic\%20Disorders\%20Fact\%20Sheet.pdf, p. 1) (Beech et al., 2016, or more discussion of the problems with paraphilias in the DSM-5 see Fedoroff, Di Gioacchino, \& Murphy, 2013). 


\section{Classification of zoophilia}

Aggrawal (2011) proposed a ten-tier classification scheme of bestiality based on his necrophilia classification scheme in which he categorized behaviours from least pathologic to most pathologic. with those individuals "pathologically less deviant" belonging in Class I (role players) and those more deviant belonging in Class X (exclusive zoophiles). Notably, he categorized the "exclusive zoophile," or somebody who only engages in sex with animals, as the most pathologic. DSM criteria (American Psychiatric Association, 2013) have solely focused on atypical sexual interest when establishing a diagnosis rather than the meaning of or motivations underlying an individual's sexual behaviours and interests. Specifically, Class I zoosexuals: humaneanimal role-players (individuals in this category do not use animals for sex. They are mere role-players and would rather that their human partners act as animals during sex, as the thought of having sex with animals causes them great excitement); and Class $\mathrm{X}$ zoosexuals (this class includes individuals who are exclusively zoosexuals. Sexual intercourse is possible only or mostly with animals. There is virtually a complete exclusion of human partners) (Aggrawal, 2011). In Aggrawal's (2011) ten-tier classification scheme, zoophilic Classes III through $\mathrm{X}$ all would come under the single diagnosis of Paraphilia Not Otherwise Specified-Zoophilia or Other Specified Paraphilic Disorder-Zoophilia. Holoyda (2017) has argued that using Aggrawal's ten-tier classification system to classify bestiality behaviours may be useful for forensic and clinical professionals in obtaining a greater understanding of what specific sex acts an individual engages in. However, it is important to point out that although "defining the specific sex acts related to bestiality can be instructive, consideration of individuals' motivations for engaging in bestiality may prove more useful to a forensic psychiatric evaluator" (Holoyda, 2017, pp. 543).

\section{Psychiatric Disorders and Zoophilia}

Yakeley and Wood (2014) pointed out that there are relatively few studies investigating the prevalence of paraphilias in psychiatric populations. However, one of the few studies (Marsh, 2010) found that $13.4 \%$ of psychiatric inpatients had a DSM-IV paraphilia (Diagnostic and statistical manual of mental disorders, 4th ed., Text Revision. Washington, DC: Author. American Psychiatric Association, 2000). Compared to patients with no paraphilias, patients with paraphilias were found to be more likely to have been admitted to hospital before and to have made a suicide attempt. Turning to forensic populations, there are a number of studies which have found that paraphilias are relatively common in forensic populations. For instance, studies have found rates as high as between 25 and $75 \%$ in sex offenders (Raymond, 1999; Dunsieth, 2004). In an earlier study, the prevalence of bestiality (both 
actual sexual contacts and sexual fantasy) was examined in a group of 20 psychiatric inpatients compared to the prevalence of bestiality in two control groups (one being 20 medical inpatients and the other group 20 psychiatric staff members). Findings showed that there was a significantly higher prevalence rate $(55 \%)$ of bestiality in the psychiatric patients compared with the control groups $(10 \%$ and $15 \%$, respectively) (Alvarez \& Freinhar, 1991).

\section{Autism Spectrum Disorders (ASD)}

Autism spectrum disorder (ASD) is a neurodevelopmental condition. ASDs are characterised by social communication and social interaction difficulties and restricted, repetitive behaviours or interests (RBRIs) (APA, 2013). It is worth pointing out here that RBRIs characterises behaviours that can include repetitive motor movements, sensory reactions, rituals, routines and restricted interests. In the DSM-5 (APA, 2013) the subtypes of ASD have been abandoned (e.g., autistic disorder and Asperger disorder) and there is now a single category of ASD (Maenner et al., 2014). Numerous studies have found that approximately four males fulfil the diagnostic criteria for ASD for every female (e.g., Fombonne 2009; Szatmari, Chawarska, Dawson, Georgiades, Landa et al., 2016; Lord, Rutter, \& Le Couteur, 1994; Volkmar, Szatmari, \& Sparrow, 1993; McLennan, Lord, \& Schopler, 1993; Brugha, McManus, Bankart, Scott, Purdon et al., 2011; Loomes, Hull, \& Mandy, 2017). Many hold the belief that the new criteria will led to a decrease in the number of individuals who received a diagnosis of ASD (e.g., Kim et al., 2014; Maenner et al., 2014; McPartland, Reichow, \& Volkmar, 2012; Taheri \& Perry, 2012).

As highlighted by Kulage and colleagues (2014) in their paper, ASD in the DSM-5 now includes only two main behaviour categories because social interaction and communication have been collapsed into one criterion. To fulfil the diagnostic criteria for ASD, an individual must meet four broad criteria which consist of meeting all of the three distinctions of the social communication and interaction (SCI) criteria and also two out of four distinctions of the RRBI criteria. With the changes in the DSM-5 there are now significantly less ways to meet the diagnostic threshold for ASD (Kulage, Smaldone, \& Cohn, 2014). There are just 11 possible combinations of ASD criteria (McPartland et al., 2012). However, there are others (e.g., Huerta, Bishop, Duncan, Hus, \& Lord, 2012; Swedo et al., 2012) who would disagree that the new DSM-5 criteria for ASD will result in a decrease in ASD diagnoses and contend instead that the changes to the diagnostic criteria in the DSM-5 will make no impact on the prevalence and will actually result in an increase in the accurate identification of ASD compared to the diagnostic criteria in the earlier versions of the DSM (Haney, 2016). 
In terms of the genetic basis for ASD, as many as eight hundred eighty-one genes have been identified as being implicated in the etiology of ASD, with a minimum of one from each chromosome (Butler, Rafi, Hossain, Stephan, \& Manzardo, 2015 (https://gene.sfari.org/)). Most cases of ASD have a genetic etiology which is unknown. There have also been a number of prenatal or perinatal environmental factors which have been found to contribute to the disorder. However, the exact mechanisms of these factors remain unclear (e.g., Geschwind, 2011; Dean, Harwood, \& Kasari, 2017; Ferri, Abel, \& Brodkin, 2018). It has been posited that risk genes may interact with sex-specific pathways which may be related to hormones or immune function, as opposed to the risk genes being sex-specific themselves (Werling, Parikshak, \& Geschwind, 2016; McCarthy \& Wright, 2017, see also Gillberg, Fernell, Kočovská, Minnis, Bourgeron, Thompson, \& Allely, 2017).

\section{ASD and Deviant Sexual Behaviour}

Over the last decade, there has been an increasing number of empirical studies exploring sexuality among individuals with ASD. The findings from these studies are "dispelling antiquated notions that ASD individuals are asexual, sexually unknowledgeable and inexperienced, and/or disinterested in relationships" (Kellaher, 2015, pp. 24). There is still much research needed to investigate paraphilic or deviant arousal sexual behaviours in individuals with ASD (Kellaher, 2015). Studies have shown adolescents and adults with high-functioning ASD have just as much capacity for sexual behaviour as individuals without an ASD diagnosis (Gilmour, Schalomon, \& Smith, 2012; Dewinter, Vermeiren, Vanwesenbeeck, Lobbestael, \& Van Nieuwenhuizen, 2015). Before such research, it was believed that individuals with ASD had little or no sociosexual experiences as a result of core social impairments and asexuality or inappropriate sexual behaviours (e.g., Wing, 1981; Ruble, \& Dalrymple, 1993). Dewinter and colleagues have argued that, in individuals with ASD, specific sensory interests may contribute to sexual behaviours (Dewinter et al., 2015, see also Allely \& Creaby-Attwood, 2016).

There are only a handful of systematic studies investigating paraphilias in individuals with ASD (Hellemans, Colson, Verbraeken, Vermeiren, \& Deboutte, 2007; Fernandes, Gillberg, Cederlund, Hagberg, Gillberg, \& Billstedt, 2016; Schöttle, Briken, Tüscher, \& Turner, 2017). The majority of publications are case studies of individuals with ASD who exhibit a paraphilia or deviant sexual behaviour (e.g., Kobayashi, 1991; Bowler \& Collacott, 1993; Chesterman \& Rutter, 1993; Cooper, Mohamed, \& Collacott, 1993; Milton, Duggan, Latham, Egan, \& Tantam, 2002; Silva, Leong, \& Ferrari, 2003; Coskun, \& Mukaddes, 2008; Dozier, Iwata, \& Worsdell, 2011; Early, Erickson, Wink, McDougle, \& Scott, 2012; Kolta \& Rossi, 2018). In their paper, Dozier and colleagues (2011) 
described the case of Alex, a 36-year-old man with an ASD diagnosis. He exhibited very poor expressive language ability. Alex had a 20-year history of inappropriate sexual (masturbatory) behaviour (ISB). This behaviour he displayed consisted of dropping to a prone position close to another person's feet and proceeded to gyrate his pelvis on the floor. Following functional analysis, Dozier and colleagues found evidence which indicated that Alex engaged in bizarre sexual behaviour when he was in the company of women who are wearing sandals (Dozier et al., 2011). To date, there have been no published case reports involving females with ASD who are engaging in paraphilic or paraphiliclike behaviours (or deviant sexual behaviours). The case reports on females which are available seem to focus on gender dysphoria or masturbatory issues which are not deviant sexual behaviours (Kellaher, 2015). It is also important to point out that nearly all case studies involving males with ASD who are engaging paraphilic behaviours also present with some type of cognitive impairment (Schöttle, Briken, Tüscher, \& Turner, 2017). How much the ASD symptomology contributes to the paraphilic behaviours in these cases is unclear.

\section{Present Study}

There still remains a lack of knowledge surrounding paraphilic or deviant arousal sexual behaviours in individuals with ASD (Kellaher, 2015). The aim of the present systematic review is to explore the literature for any empirical study, case study or discussion/review paper surrounding individuals with ASD and zoophilia or bestiality.

\section{Methods}

A total of five internet-based bibliographic databases were searched in order to identify studies which explored ASD in relation to zoophilia (including case studies as well as empirical studies). The five databases included: PsycARTICLES Full Text, [Database Field Guide] AMED (Allied and Complementary Medicine) 1985 to May 2019, [Database Field Guide] PsycEXTRA 1908 to April 16, 2019, [Database Field Guide] PsycINFO 1806 to April Week 5 2019, [Database Field Guide] Ovid MEDLINE(R) and Epub Ahead of Print, In-Process \& Other Non-Indexed Citations and Daily 1946 to May 03, 2019. The search on the five electronic databases was performed on the $10^{\text {th }}$ May 2019. The search adhered to PRISMA guidelines (Liberati et al., 2009; Moher, Liberati, Tetzlaff, \& Altman, 2009). The search was not restricted by date. Search terms were applied to title. The following search criteria were entered into the five databases: (ASD or "autis* spectrum disorder*" or autis* or "autis* 
spectrum condition*" or asperger*).m_titl. AND (bestiality or zoophilia* or zoosexual* or zoophilism* or zooerasty or zooerastia* or bestiosexualit* or bestials or bestialities or zoophile* or zoophilic* or zoosadism or bestialsadism).m_titl.

This search returned two articles. Following the removal of duplications there was one article. This one article was found to be relevant. As well as the searches carried out on the five databases listed above, a variety of permutations of the search terms entered into the databases were entered into Googlescholar. Googlescholar was searched thoroughly for any potentially relevant articles not identified through the search carried out on the five databases. Some examples of the search term groupings included: ASD AND bestiality; autism AND bestiality; autism AND zoophilia; asperger's syndrome AND bestiality; asperger's syndrome AND zoophilia and autism AND zoophiles. This resulted in a further four relevant articles which were identified as being relevant to the present review as they both included a description of a case involving an individual with ASD who had engaged in zoophilia or bestiality (see Figure 1. For PRISMA Flow Diagram of this process). Lastly, given the relatively lack of research in this area, the present systematic review adopted an inclusive approach. There were no exclusion criteria for the papers identified which investigated ASD in relation to bestiality or zoophilia or included a discussion of a case study of someone with ASD who had engaged in zoophilia or bestiality. All forms of sources will be considered for inclusion including academic peer reviewed articles, reports, discussion papers, book chapters, conference abstracts, dissertations, etc. In all the papers which were relevant for inclusion in the present review the reference section was examined for any potentially relevant articles.

\section{Results}

Only one article was identified as being relevant in the present review (Chandradasa \& Champika, 2017), three further articles included a description of a case involving someone with ASD who engaged in zoophilia or bestiality (Jones, 2007; Freckelton, 2013; Kellaher, 2015) and another paper, although not the focus of the study, found one person with $\mathrm{AD}$ who had several paraphilias including olfactophilia, podophilia and zoophilia in a sample of 20 institutionalized, male adolescents and young adults with Autistic Disorder (AD) and borderline/mild mental retardation (MR) (Hellemans, Roeyers, Leplae, Dewaele, \& Deboutte, 2010). The relevant information will be discussed in turn.

Firstly, Chandradasa and Champika (2017) reported in their paper a case of SB a 17-year-old male adolescent from Sri Lanka with high functioning ASD presenting with features of zoophilia. He 
had intelligence and academic abilities within the normal range. The amount of time that SB was spending at his grandparents' cattle house had been increasing. One day he was discovered masturbating close to the cows and was also later found engaging in penetrative sex with a heifer. Following his parent's discovery of his deviant sexual behaviours, they sought traditional healing for SB known as 'thovil' which is a demonic ritual of exorcist nature. The purpose of thovil is to chase away any malevolent spirits which are believed to give rise to states of mind and body which are pathological (Kuruppuarachchi \& Rajakaruna, 1999). The clinical evaluation found that SB, over the previous 12 months, "had recurrent, intense sexual fantasies about having sexual intercourse with cattle, watching them mate and masturbating while observing them" (Chandradasa \& Champika, 2017; pp. 487).

According to Aggrawal's ten-tier classification scheme, SB's behaviour could be categorised as class VII which refers to individuals who are regular zoophiles. They do not prefer intercourse with humans and have a preference for sex with animals. He had no history of having had any romantic or sexual relationship with another human. SB reported that he had viewed online human pornography. However, he reported that, compared to watching animals, he did not get the same enjoyment from it. SB did not report having any sexual interest in non-living objects, children or adult males. He had significantly more interest in animals when compared to adult females. He preferred sexual fantasies and behaviours related to animals. The conclusion from the clinical evaluation with SB was that he fulfilled the DSM-5 diagnostic criteria for ASD and for other specified paraphilic disorder. A normal sex hormone profile was found. For more than six months, SB had experienced 'recurrent intense sexual fantasies, urges and behaviours' related to animals. The decision make for treatment was a combination of cognitive-behaviour therapy and a selective serotonin reuptake inhibitor (Chandradasa \& Champika, 2017). Chandradasa and Champika (2017) argued that SB's persistent social difficulties (which was part of his ASD symptomology) played a contributory role in the development of his paraphilic disorder. This sexually deviant behaviours caused SB significant levels of distress.

In the paper by Kellaher (2015), she discusses a case where she evaluated a young man with ASD whose interest in wolves as a child transformed into a preferential canine zoophilia as an adolescent. He began during puberty, masturbating to images of females who were dressed up like wolves - individuals who dress up like animals are referred to as "furries". Not long after, he started watching online hardcore bestiality videos involving dogs. He was eventually arrested after having entered into the yard of a stranger and masturbating as he touched a dog. He admitted that, as a child, he had an interest in wolves which was insatiable. He was particularly attracted to the look of their soft 
fur. When he was an adolescent, he attention was drawn to the scrotums of large dogs and he experienced urges to touch the dogs' scrotums. He reported feeling excited sexually by looking at and touching the fur and scrotum and soft fur of a large dogs that are wolf-like. For his sexual arousal, he was particularly interested in the sensory parts of 'the whole' for his sexual arousal - the large scrotum most notably. This is common in individuals with ASD. This focus on sensory parts of 'the whole' was what subsequently contributed to his offending behaviour (Kellaher, 2015).

In his paper, Freckelton (2013) discusses the case of Director of Public Prosecutions v HPW (2011) where the Victorian Court of Appeal heard an appeal which was brought by the prosecution who contended that the sentencing judge at first instance had incorrectly identified a causal relationship between HPW's Asperger's Disorder (AD) and his sexual offending, had "erred in imposing a manifestly inadequate sentence and had inadequately cumulated the penalties he imposed for a significant number of sex offences" (Freckelton, 2013, pp. 162). In this first instance, he was found guilty of eight charges (three of these eight charges were representative of numerous occasions where he had carried out sex offending against his biological daughter when she was 11 and 12 years of age. The sex offending committed against his biological daughter involved numerous occasions of oral, digital and anal penetration in addition to instances of masturbation and of getting the family dog to lick his daughter's vagina. HPW admitted sodomising his daughter when the police interviewed him and he said that it was "just as an experiment" and that "it was just sexual gratification for myself". He also told police that he was "probably a psycho". HPW was 47 years of age and had no history of criminal convictions. HPW had been in the army for some time before being discharged in 2007 after failing to return some hand grenades. HPW had two children from a marriage which lasted more than 10 years. He subsequently had a relationship with another women which involved bestiality and anal sex. Following assessment with a psychologist, it was considered that when "he realised what he was doing" he immediately ceased the offending with his daughter. HPW only received a diagnosis of AD after the criminal charges were laid. It was the view of the Psychologist, Dr Kennedy, that HPW had no appreciation or understanding of the negative impact his actions were having on his daughter while he was carrying out his offending. However, Dr Kennedy stated that following appropriate support, HPW had since acquired both empathy and remorse which was believed to be genuine. HPW had not engaged in any grooming process which is something which is communing found in cases of sex offending. During the sentencing decision, the court did not consider HPW's diagnosis of AD had any impact on his moral blameworthiness. However, the court did accept that his diagnosis of AD was a mitigating factor in that it was likely to be more of a burden for his when it came to him to his custodial sentence experience (see Allely, 2015). It ordered an increase to his sentence from seven and a half 
years' imprisonment with a non-parole period of five years and six months to nine years and six months' imprisonment with a non-parole period of six years and six months (Freckelton, 2013). As highlighted by Freckelton, judges' evaluation of the relevance of AD will vary across cases (Freckelton, 2013).

Jones (2007) briefly discussed the case of a young man with ASD who was engaging in bestiality. He was meeting people on online and making arrangement to visit their homes in order to have intercourse with their pets. He does not appreciate or fully understand the potential risks of going into strangers' homes as a result of his ASD. Jones highlights in the brief discussion of this case that nothing legally could be done regarding the risks for this young man with ASD given that he was not a minor (Jones, 2007). Lastly, Hellemans and colleagues (2010) carried out a study involving group home caregivers of 20 institutionalised, male adolescents and young adults with Autistic Disorder (AD) and borderline/mild mental retardation (MR) and another group comprising of group home caregivers of 19 institutionalised, male adolescents and young adults with borderline/mild MR, without AD. Both groups were interviewed using the Interview Sexuality Autism-Revised (ISA-R). Findings revealed that in the group with $\mathrm{AD}$ there were some deviant sexual behaviours including stereotyped sexual interests; sensory fascinations with a sexual connotation and paraphilia. However, no deviant sexual behaviours were identified in the group with MR. Relevant to this review, Hellemans and colleagues found one person with $\mathrm{AD}$ had several paraphilias including olfactophilia (which refers to the paraphilia for, or sexual arousal by, smells and odours which come from the body, particularly in the sexual areas), podophilia (a paraphilia which involves the sexual attraction to feet; foot fetishism) and zoophilia (Hellemans et al., 2010).

\section{Discussion}

This systematic review is the first to explore the literature for any empirical study, case study or discussion/review paper surrounding individuals with ASD and zoophilia or bestiality. The review revealed a dearth of literature in the field. It identified only one article which was relevant in the present review in that the association between zoophilia and ASD was the focus of the paper (Chandradasa \& Champika, 2017), three further articles were identified which included a description of a case involving someone with ASD who engaged in zoophilia or bestiality (Jones, 2007; Freckelton, 2013; Kellaher, 2015) and another paper, although not the focus of the study, found one person with AD who had several paraphilias including olfactophilia, podophilia and zoophilia in a 
sample of 20 institutionalized, male adolescents and young adults with Autistic Disorder (AD) and borderline/mild mental retardation (MR) (Hellemans, Roeyers, Leplae, Dewaele, \& Deboutte, 2010).

All the case studies clearly highlight some of the ASD symptomology that can contribute to engaging in bestiality or zoophilia. ASD could be associated with zoophilia in a number of ways. For instance, ASD could be associated with sexual interest in animals as a highly restricted fixated interest that is abnormal in intensity which is related to criteria three in the second domain of the ASD diagnostic criteria: 'B Restricted repetitive patterns of behavior, interests, or activities' (namely, B3 Highly restricted, fixated interests that are abnormal in intensity or focus; (such as strong attachment to or preoccupation with unusual objects, excessively circumscribed or perseverative interests) (DSM5, 2013). Also, it could be related to the 3rd criteria of the first domain of the ASD diagnostic criteria in which the person has deficits in developing and maintaining social relationships (specifically, A3 Deficits in developing and maintaining relationships, appropriate to developmental level (beyond those with caregivers); ranging from difficulties in adjusting behavior to suit different social contexts through difficulties in sharing imaginative play and in making friends to an apparent absence of interest in people) (DSM-5, 2013). This deficit may prevent some individuals with ASD of having normal intimate and sexual relationships with other humans. Critically, this lack of (or reduced) opportunity to have normal sexual relationships between humans might lead to an increase in other forms of sexual expression (Dr Miyuru Chandradasa, 2019, personal communication). In addition, we need to consider the possible association with comorbid intellectual disability in a significant proportion of individuals with ASD. The case report in paper by Chandradasa and Champika (2017) was on a person with high functioning ASD (Dr Miyuru Chandradasa, 2019, personal communication). It would be useful to investigate zoophilia and bestiality in individuals with ASD and intellectual disability as well as individuals with "pure" ASD. It is well-established that there is a high co-morbidity between ASD and intellectual disability (e.g., Matson \& Shoemaker, 2009).

It is also important to consider that "having highly restricted interests and having sensory peculiarities in ASD may possibly set the stage for developing fetishism and other paraphilias in individuals with certain sensory profiles among other factors" (Kellaher, 2015, pp. 30). These highly restricted interests related to the third criteria in first domain of the ASD diagnostic criteria, namely, 'B4 Hyper- or hypo-reactivity to sensory input or unusual interest in sensory aspects of environment; (such as apparent indifference to pain/heat/cold, adverse response to specific sounds or textures, excessive smelling or touching of objects, fascination with lights or spinning objects)' (DSM-5, 2013). Take the relevant case described by Kellaher (2015), which involved the young man with ASD whose 
interest in wolves as a child transformed into a preferential canine zoophilia as an adolescent. This young man had admitted that he was sexually excited at seeing and touching the fur and scrotum of a large wolf-like dog. This is an example of an interest in the sensory parts of 'the whole' for sexual excitement. Kellaher argues that this partialism or body part fetishism (which is 'part' oriented as opposed to 'whole' other person-oriented) is relatively commonly identified in individuals with ASD. So, for instance, "just as an ASD individual may be interested in the wheels of a car, he may also be drawn sexually to the feet or hair of another person" (Kellaher, 2015, pp. 30). Indeed, this is consistent with a number of published case studies involving individuals with ASD who have a paraphilia or sexual interest in a particular body part such as feet (e.g., Dozier et al., 2011). Diagnosing cases of paraphilic disorders (such as zoophilia) in individuals with ASD can be challenging. One of the main reasons for this is that specific behaviours can be stimulated by sensory (and other) disorders, with no sexual element being involved. However, restricted, repetitive interests and behaviors which have no sexual element in childhood may, in adolescence, develop into sexualised or sexual, restricted, repetitive interests. In other words, "early, inadvertent conditioning to sensory stimuli that is appealing during pre-puberty may lead to a powerful union between specific ASD sensory-seeking and sexual arousal through masturbation" (Kellaher, 2015, pp. 30). The idea of early conditioning to deviant stimuli has been discussed before (Singh \& Coffey, 2012). However, it has never been examined as a factor by itself and studied empirically (Kellaher, 2015; Kellaher, 2019, personal communication).

As highlighted by Kellaher (2015), it is possible that deviant sexual behaviour, such as zoophilia, may be the result of a paraphilia. However, it is also important to consider whether such behaviours represent "counterfeit" deviant sexual behaviour in individuals with ASD. Counterfeit deviance is a term which is used to describe sexual behaviour that seems to arise from a paraphilia but may actually stem from impaired social skills and a lack of sexual knowledge and experience (Hingsburger, Griffiths, \& Quinsey, 1991) relating to criteria one in the first domain of the ASD diagnostic criteria: 'A1 Deficits in social-emotional reciprocity; ranging from abnormal social approach and failure of normal back and forth conversation through reduced sharing of interests, emotions, and affect and response to total lack of initiation of social interaction' (DSM-5, 2013). The issue of counterfeit deviant sexual behaviour stemming from social skills impairments has previously been explored in the literature, typically in relation to sex-offending behaviour (Griffiths, Hingsburger, Hoath, \& Ioannou, 2013). Take the example of a young man with ASD who obsessively collects female silk undergarments may have no sexual interest in the collection, though it would be considered to sexually motivated by others (Kellaher, 2015). Further support for this argument comes from a study by Beetz (2002) who examined a community sample of 113 men and three women who had all reported 
having had sexual relations with animals. Findings from the study revealed that interpersonal relationships difficulties, on average, were more of a problem for the individuals who had engaged in sexual relations with animals.

\section{Clinical Implications and Recommendations}

As mentioned briefly in the introduction, individuals with ASD often experience prejudicial stereotypes that they are asexual, hyper- or hypo sexual, child-like and dependent, and/or uninterested in sex (Bennett, Webster, Goodall, \& Rowland, 2018; MacKenzie, 2018). Also, MacKenzie (2018) have also highlighted that their sexuality is considered by some be problematic and needs to be 'treated' or managed. Some of the stereotypes surrounding the sexuality of individuals with ASD are perpetuated by some of the features of ASD such as aversion to being touched by others and that because they are 'unemotional' they would not be interested in sexual relationships (Kellaher, 2015; MacKenzie, 2018). As young people with ASD enter into adulthood, they may find themselves faced with significant difficulties in developing and maintaining social and romantic relationships as a result of their social impairments and sexual 'anomalies' (Henault \& Attwood, 2006; MacKenzie, 2018).

It has been argued that the lack of support and services (in schools, etc) to help autistic adults with ASD develop the necessary skills to help them understand the social nuances of dating, intimacy and relationships further exacerbate these difficulties faced by individuals with ASD (MacKenzie, 2018). Individuals with ASD are much less likely to be able to get sexual health information from their friends or peer groups, media, school and parents (Bleakley, Hennessy, Fishbein, \& Jordan, 2009). Adolescents with ASD frequently do not have links with extensive peer groups where informal discussions relating to sex occur (Mehzabin \& Stokes, 2011). It has also been identified that individuals with ASD are less likely to receive sex and sexuality education, or an education in sex and social relationships that is tailored to their specific needs (MacKenzie, 2018). Moreover, there is an increasing number of studies indicating that individuals with ASD are also less likely to gain knowledge about sex from their parents or teachers. It has also been suggested that they more often access the media and pornography in an attempt to gain information about sex. This can often lead to unintentional online offending in some cases (see Allely \& Dubin, 2018). Many individuals with ASD have insight into their own impairments in relation to romantic relationships which has an adverse impact on their social relationships (Stokes, Newton, \& Kaur, 2007; Brown-Lavoie, Viecili, \& Weiss, 2014; Barnett \& Maticka-Tyndale, 2015; Parchomiuk, 2018). 
In a survey with individuals with ASD and typically developing individuals, Mehzabin and Stokes (2011) found that individuals with ASD have less adaptive sexual knowledge and behaviours, reported less social behaviour (e.g., going out with friends), less education about sex and sexuality and less sexual experience (Mehzabin \& Stokes, 2011). In a study by Corona and colleagues (2016) findings suggested that parents of adolescents with ASD believe that their children are interested in sexual and romantic relationships. However, they are not aware of how to effectively and appropriately instigate conversations with their child with ASD regarding such topics (Corona, Fox, Christodulu, \& Worlock, 2016). As highlighted by Corona and colleagues (2016), there is a general consensus that adolescents with ASD need to be able to access education about sexuality and relationships needs (Travers \& Tincani, 2010; Chan, \& John, 2012; Gilmour, Smith, \& Schalomon, 2014; Sullivan \& Caterino, 2008). The education would consist of the core topics covered in standard sex education programmes (e.g., sexual development, safe sex, contraception, and sexually-transmitted infections) in addition to topics such as: social skills development (e.g., empathy, perspective-taking) and social conventions relating to flirting and dating (Travers \& Tincani, 2010; Chan, \& John, 2012; Gilmour, Smith, \& Schalomon, 2014).

In their semi-structured qualitative interviews with 18 parents of children with ASD (aged 613 years), Ballan (2012) found that some parents believed that broad-ranging discussions about sexuality and relationships would not be relevant. Parents reported that their sexuality-related discussions with their child did not include topics relating to their child's future social and sexual behaviours (Ballan, 2012). Consistent with this, in the study by Mackin and colleagues (2016) they found that few parents of children with ASD could quickly imagine the likelihood of their child ever experiencing a romantic relationship (Mackin, Loew, Gonzalez, Tykol, \& Christensen, 2016). Based on focus groups with parents of children and adolescents with ASD, Nichols and Blakeley-Smith (2009) found that the parents shared the same concerns such as worrying about their child with ASD facing legal problems as a result of their own actions. Additionally, confusion surrounding what healthy sexuality might look like in someone with ASD was also reported by some of the parents (Nichols \& Blakeley-Smith, 2009).

It is unsurprising that parents of children with ASD across the autism spectrum experience such difficulties in their sexuality-related discussions with their child given that it is common for parents of typically developing children to report that they put off or neglected discussing sex related topics with their child because of feelings of discomfort, their perceived inadequate or inaccurate knowledge, etc 


\section{Future Research Directions}

There are numerous studies which have found that individuals who engage in zoophilic behaviours are at increased risk of perpetrating other criminal offenses (e.g., Fleming, Jory, \& Burton, 2002; Hensley, Tallichet, \& Singer, 2006; Hensley, Tallichet, \& Dutkiewicz, 2010). It has been suggested that zoophilic acts may be a potential useful indicator for future risk of sexual and also nonsexual violent behaviour (Holoyda \& Newman, 2014). Moreover, Abel carried out a survey of 44,202 adult men and found that the single strongest predictor for engaging in future child sexual abuse was a history of bestiality (Abel, 2008). Another study found childhood bestiality to be the only method of animal cruelty which was able to predict future 'recurrent interpersonal violence' (Henderson et al., 2011). However, Ranger and Fedoroff (2014), amongst others, have emphasised the potential limitations of the literature to date. For instance, most studies on bestiality and violence risk comprise of forensic samples with no control groups (Holoyda et al., 2016). Future studies need to address this and also explore the violence risk in individuals with ASD who engaged in bestiality.

As highlighted by Hellemans and colleagues (2011), there is a need for more research investigating the prevalence of paraphilia, in particular zoophilia (as well as bestiality) in persons with ASD. Also, more researched is needed surrounding the development and evaluation of specifically 
tailored sexuality education programmes which help promote positive transitions for adolescents with ASD (Corona, Fox, Christodulu, \& Worlock, 2016).

\section{Conclusions}

This systematic review highlighted only a small number of papers which have looked at zoophilia or bestiality in individuals with ASD. It is crucial that there are more case studies and empirical investigations into this area in order to gain more of an understanding of how ASD symptomology can contribute to paraphilias such as zoophilia and also the role they may play in bestiality. The knowledge gained from such research will help increase our understanding of how certain features of ASD may contribute to such behaviours. Also, it will help aid identification of such behaviours in individuals with ASD and also inform the develop of appropriate interventions/treatments. As also highlighted in the clinical implications and recommendations section it is important that individuals with ASD have access to appropriate and timely sex education and that parents are supported by healthcare professionals to engage with their children with ASD in such interactions across the autism spectrum irrespective of the parent's expectations (Holmes, Himle, \& Strassberg, 2016).

\section{Conflicts of Interest}

The authors have no conflicts of interest to declare.

\section{Funding}

This paper was unfunded. 


\section{References}

Abel, G. (2008). What can 44,000 men and 12,000 boys with sexual behavior problems teach us about preventing sexual abuse? Paper presented at the annual training conference of the California coalition on sexual offending, San Francisco, California.

Aggrawal, A. (2011). A new classification of zoophilia. Journal of Forensic and Legal Medicine, $18(2), 73-78$.

Allely, C. S., \& Dubin, L. (2018). The contributory role of autism symptomology in child pornography offending: why there is an urgent need for empirical research in this area. Journal of Intellectual Disabilities and Offending Behaviour, 9(4), 129-152.

Allely, C., \& Creaby-Attwood, A. (2016). Sexual offending and autism spectrum disorders. Journal of Intellectual Disabilities and Offending Behaviour, 7(1), 35-51.

Allely, C. S. (2015). Experiences of prison inmates with autism spectrum disorders and the knowledge and understanding of the spectrum amongst prison staff: a review. Journal of Intellectual Disabilities and Offending Behaviour, 6(2), 55-67.

Alvarez, W.A., \& Freinhar, J.P. (1991) A prevalence study of bestiality (zoophilia) in psychiatric inpatients, medical in-patients, and psychiatric staff. International Journal of Psychosomatics, 38, 4547.

American Psychiatric Association. (2013). Diagnostic and statistical manual of mental disorders. 5th ed. Washington, DC: American Psychiatric Association.

American Psychiatric Association (2000). Diagnostic and statistical manual of mental disorders (4th ed., Text Revision). Washington, DC: Author.

Ballan, M. S. (2012). Parental perspectives of communication about sexuality in families of children with autism spectrum disorders. Journal of Autism and Developmental Disorders, 42(5), 676-684.

Barnett, J. P., \& Maticka-Tyndale, E. (2015). Qualitative exploration of sexual experiences among adults on the autism spectrum: implications for sex education. Perspectives on Sexual and Reproductive Health, 47(4), 171-179. 
Beech, A. R., Miner, M. H., \& Thornton, D. (2016). Paraphilias in the DSM-5. Annual Review of Clinical Psychology, 12, 383-406.

Beetz, A. (2002). Love, violence, and sexuality in relationships between humans and animals. Aachen: Shaker Verlag.

Beetz, A. M. (2004). Bestiality/zoophilia: A scarcely investigated phenomenon between crime, paraphilia, and love. Journal of Forensic Psychology Practice, 4(2), 1-36.

Bennett, M., Webster, A. A., Goodall, E., \& Rowland, S. (2018). Intimacy and Romance Across the Autism Spectrum: Unpacking the "Not Interested in Sex" Myth. In Life on the Autism Spectrum (pp. 195-211). Springer, Singapore.

Bleakley, A, Hennessy, M, Fishbein, M, \& Jordan, A (2009). How sources of sexual information relate to adolescents' beliefs about sex. American Journal of Health Behaviour, 33, 37-48.

Bowler, C., \& Collacott, R. A. (1993). Cross-dressing in men with learning disabilities. The British Journal of Psychiatry, 162(4), 556-558.

Brown-Lavoie, S. M., Viecili, M. A., \& Weiss, J. A. (2014). Sexual knowledge and victimization in adults with autism spectrum disorders. Journal of Autism and Developmental Disorders, 44(9), 2185 2196.

Brugha, T. S., McManus, S., Bankart, J., Scott, F., Purdon, S., Smith, J., ... \& Meltzer, H. (2011). Epidemiology of autism spectrum disorders in adults in the community in England. Archives of General Psychiatry, 68(5), 459-465.

Butler, M. G., Rafi, S. K., Hossain, W., Stephan, D. A., \& Manzardo, A. M. (2015). Whole exome sequencing in females with autism implicates novel and candidate genes. International Journal of Molecular Sciences, 16(1), 1312-1335.

Chan, J., \& John, R. M. (2012). Sexuality and sexual health in children and adolescents with autism. The Journal for Nurse Practitioners, 8(4), 306-315.

Chandradasa, M., \& Champika, L. (2017). Zoophilia in an adolescent with high-functioning autism from Sri Lanka. Australasian Psychiatry, 25(5), 486-488. 
Chesterman, P., \& Rutter, S. C. (1993). Case report: Asperger's syndrome and sexual offending. The Journal of Forensic Psychiatry, 4(3), 555-562.

Cooper, S. A., Mohamed, W. N., \& Collacott, R. A. (1993). Possible Asperger's syndrome in a mentally handicapped transvestite offender. Journal of Intellectual Disability Research, 37, 189-194.

Croft, C. A., \& Asmussen, L. (1992). Perceptions of mothers, youth, and educators: A path toward détente regarding sexuality education. Family Relations, 452-459.

Corona, L. L., Fox, S. A., Christodulu, K. V., \& Worlock, J. A. (2016). Providing education on sexuality and relationships to adolescents with autism spectrum disorder and their parents. Sexuality and Disability, 34(2), 199-214.

Coskun, M., \& Mukaddes, N. M. (2008). Mirtazapine treatment in a subject with autistic disorder and fetishism. Journal of Child and Adolescent Psychopharmacology, 18(2), 206-209.

Dean, M., Harwood, R., \& Kasari, C. (2017). The art of camouflage: Gender differences in the social behaviors of girls and boys with autism spectrum disorder. Autism, 21(6), 678-689.

Dewinter, J., Vermeiren, R., Vanwesenbeeck, I., Lobbestael, J., \& Van Nieuwenhuizen, C. (2015). Sexuality in adolescent boys with autism spectrum disorder: Self-reported behaviours and attitudes. Journal of Autism and Developmental Disorders, 45(3), 731-741.

Dozier, C. L., Iwata, B. A., \& Worsdell, A. S. (2011). Assessment and treatment of foot—shoe fetish displayed by a man with autism. Journal of Applied Behavior Analysis, 44(1), 133-137.

Dunsieth Jr, N. W., Nelson, E. B., Brusman-Lovins, L. A., Holcomb, J. L., Beckman, D., Welge, J. A., ... \& McElroy, S. L. (2004). Psychiatric and legal features of 113 men convicted of sexual offenses. Journal of

Clinical Psychiatry, 65, 293-300.

Fedoroff, J. P., Di Gioacchino, L., \& Murphy, L. (2013). Problems with paraphilias in the DSM-5. Current Psychiatry Reports, 15(8), 363. 
Federoff, J. P., \& Marshall, W. L. (2010). Paraphilias. In Cognitive-Behavioural Therapy for Refractory Cases: Turning Failure into Success (eds D McKay, JS Abramowitz, S Taylor): 369-84. American Psychological Association.

Fernandes, L. C., Gillberg, C. I., Cederlund, M., Hagberg, B., Gillberg, C., \& Billstedt, E. (2016). Aspects of sexuality in adolescents and adults diagnosed with autism spectrum disorders in childhood. Journal of Autism and Developmental Disorders, 46(9), 3155-3165.

Ferri, S. L., Abel, T., \& Brodkin, E. S. (2018). Sex differences in autism spectrum disorder: a review. Current Psychiatry Reports, 20(2), 9.

Fleming, W. M., Jory, B., \& Burton, D. L. (2002). Characteristics of juvenile offenders admitting to sexual activity with nonhuman animals. Society and Animals, 10(1), 31-45.

Fombonne, E. (2009). Epidemiology of pervasive developmental disorders. Pediatric Research, 65(6), $591-598$.

Frances, A., \& First, M. B. (2011). Hebephilia is not a mental disorder in DSM-IV-TR and should not become one in DSM-5. Journal of the American Academy of Psychiatry and the Law Online, 39(1), 78-85.

Freckelton, I. (2013). Forensic issues in autism spectrum disorder: learning from court decisions. In Recent Advances in Autism Spectrum Disorders-Volume II. InTech.

Geschwind, D. H. (2011). Genetics of autism spectrum disorders. Trends in Cognitive Sciences, 15(9), 409-416.

Gillberg, C., Fernell, E., Kočovská, E., Minnis, H., Bourgeron, T., Thompson, L., \& Allely, C. S. (2017). The role of cholesterol metabolism and various steroid abnormalities in autism spectrum disorders: A hypothesis paper. Autism Research, 10, 1022-1044.

Gilmour, L., Schalomon, P. M., \& Smith, V. (2012). Sexuality in a community based sample of adults with autism spectrum disorder. Research in Autism Spectrum Disorders, 6(1), 313-318.

Gilmour, L., Smith, V., \& Schalomon, M. (2014). Sexuality and ASD: current state of research. In: Patel, V.B., 
et al. (eds.), Comprehensive guide to autism (pp. 569-584). Springer, New York, NY.

Griffiths, D., Hingsburger, D., Hoath, J., \& Ioannou, S. (2013). 'Counterfeit deviance' revisited. Journal of Applied Research in Intellectual Disabilities, 26(5), 471-480.

Haney, J. L. (2016). Autism, females, and the DSM-5: Gender bias in autism diagnosis. Social Work in Mental Health, 14(4), 396-407.

Hellemans, H., Colson, K., Verbraeken, C., Vermeiren, R., \& Deboutte, D. (2007). Sexual behavior in high-functioning male adolescents and young adults with autism spectrum disorder. Journal of Autism and Developmental Disorders, 37(2), 260-269.

Hellemans, H., Roeyers, H., Leplae, W., Dewaele, T., \& Deboutte, D. (2010). Sexual behavior in male adolescents and young adults with autism spectrum disorder and borderline/mild mental retardation. Sexuality and Disability, 28(2), 93-104.

Hénault, I., \& Attwood, T. (2006). Asperger's syndrome and sexuality: From adolescence through adulthood. Jessica Kingsley Publishers.

Henderson, B. B., Hensley, C., \& Tallichet, S. E. (2011). Childhood animal cruelty methods and their link to adult interpersonal violence. Journal of Interpersonal Violence, 26(11), 2211-2227.

Hensley, C., Tallichet, S. E., \& Dutkiewicz, E. L. (2010). Childhood bestiality: A potential precursor to adult interpersonal violence. Journal of Interpersonal Violence, 25(3), 557-567.

Hensley, C., Tallichet, S. E., \& Singer, S. D. (2006). Exploring the possible link between childhood and adolescent bestiality and interpersonal violence. Journal of Interpersonal Violence, 21(7), 910923.

Huerta, M., Bishop, S. L., Duncan, A., Hus, V., \& Lord, C. (2012). Application of DSM-5 criteria for autism spectrum disorder to three samples of children with DSM-IV diagnoses of pervasive developmental disorders. American Journal of Psychiatry, 169(10), 1056-1064.

Hingsburger, D., Griffiths, D., \& Quinsey, V. (1991). Detecting counterfeit deviance: Differentiating sexual deviance from sexual inappropriateness. The Habilitative Mental Healthcare Newsletter, 10(9), $51-54$. 
Holoyda, B., \& Newman, W. (2014). Zoophilia and the law: legal responses to a rare paraphilia. Journal of the American Academy of Psychiatry and the Law Online, 42(4), 412-420.

Holoyda, B. J., \& Newman, W. J. (2016). Childhood animal cruelty, bestiality, and the link to adult interpersonal violence. International Journal of Law and Psychiatry, 47, 129-135.

Holoyda, B. (2017). Bestiality in forensically committed sexual offenders: a case series. Journal of Forensic Sciences, 62(2), 541-544.

Holoyda, B., Sorrentino, R., Friedman, S. H., \& Allgire, J. (2018). Bestiality: An introduction for legal and mental health professionals. Behavioral Sciences and the Law.

Holmes, L. G., Himle, M. B., \& Strassberg, D. S. (2016). Parental romantic expectations and parentchild sexuality communication in autism spectrum disorders. Autism, 20(6), 687-699.

Ivey, J. K. (2004). What do parents expect? A study of likelihood and importance issues for children with autism spectrum disorders. Focus on Autism and Other Developmental Disabilities, 19(1), 27-33. Jones, G. (2007). Vulnerable Adults What are the Safety Checks?. http://www.youthresponseguidecwr.org/uploads/1/3/5/0/13500687/safeguards for_vulnerable adults discussion_paper_october_2007.pdf Accessed on 3rd January 2019.

Kellaher, D. C. (2015). Sexual behavior and autism spectrum disorders: an update and discussion. Current Psychiatry Reports, 17(4), 25.

Kim, Y. S., Fombonne, E., Koh, Y. J., Kim, S. J., Cheon, K. A., \& Leventhal, B. L. (2014). A comparison of DSM-IV pervasive developmental disorder and DSM-5 autism spectrum disorder prevalence in an epidemiologic sample. Journal of the American Academy of Child and Adolescent Psychiatry, 53(5), 500-508.

Kobayashi, R. (1991). Psychosexual development of autistic children in adolescence. Japanese Journal of Child and Adolescent Psychiatry, 32(3), 1-14.

Kolta, B., \& Rossi, G. (2018). Paraphilic Disorder in a Male Patient with Autism Spectrum Disorder: Incidence or Coincidence. Cureus, 10(5).

Kulage, K. M., Smaldone, A. M., \& Cohn, E. G. (2014). How will DSM-5 affect autism diagnosis? A systematic literature review and meta-analysis. Journal of Autism and Developmental Disorders, 44(8), 1918-1932. 
Kuruppuarachchi, K. A., \& Rajakaruna, R. R. (1999). Psychiatry in Sri Lanka. Psychiatrist, 1, 686688.

Liberati, A., Altman, D. G., Tetzlaff, J., Mulrow, C., Gøtzsche, P. C., Ioannidis, J. P., ... \& Moher, D. (2009). The PRISMA statement for reporting systematic reviews and meta-analyses of studies that evaluate health care interventions: explanation and elaboration. PLoS Medicine, 6(7), e1000100.

Loomes, R., Hull, L., \& Mandy, W. P. L. (2017). What is the male-to-female ratio in autism spectrum disorder? A systematic review and meta-analysis. Journal of the American Academy of Child and Adolescent Psychiatry, 56(6), 466-474.

Lord, C., Rutter, M., \& Le Couteur, A. (1994). Autism Diagnostic Interview-Revised: a revised version of a diagnostic interview for caregivers of individuals with possible pervasive developmental disorders. Journal of Autism and Developmental Disorders, 24(5), 659-685.

Mackin, M. L., Loew, N., Gonzalez, A., Tykol, H., \& Christensen, T. (2016). Parent perceptions of sexual education needs for their children with autism. Journal of Pediatric Nursing, 31(6), 608-618.

MacKenzie, A. (2018). Prejudicial stereotypes and testimonial injustice: Autism, sexuality and sex education. International Journal of Educational Research, 89, 110-118.

Maenner, M. J., Rice, C. E., Arneson, C. L., Cunniff, C., Schieve, L. A., Carpenter, L. A., ... \& Durkin, M. S. (2014). Potential impact of DSM-5 criteria on autism spectrum disorder prevalence estimates. JAMA Psychiatry, 71(3), 292-300.

Marsh, P. J., Odlaug, B. L., Thomarios, N., Davis, A. A., Buchanan, S. N., Meyer, C. S., \& Grant, J. E. (2010). Paraphilias in adult psychiatric inpatients. Annals of clinical psychiatry: official journal of the American Academy of Clinical Psychiatrists, 22(2), 129-134.

Matson, J. L., \& Shoemaker, M. (2009). Intellectual disability and its relationship to autism spectrum disorders. Research in Developmental Disabilities, 30(6), 1107-1114.

McCarthy, M. M., \& Wright, C. L. (2017). Convergence of sex differences and the neuroimmune system in autism spectrum disorder. Biological Psychiatry, 81(5), 402-410.

McLennan, J. D., Lord, C., \& Schopler, E. (1993). Sex differences in higher functioning people with autism. Journal of Autism and Developmental Disorders, 23(2), 217-227. 
McManus, M. A., Hargreaves, P., Rainbow, L., \& Alison, L. J. (2013). Paraphilias: definition, diagnosis and treatment. F1000prime Reports, 5.

McPartland, J. C., Reichow, B., \& Volkmar, F. R. (2012). Sensitivity and specificity of proposed DSM-5 diagnostic criteria for autism spectrum disorder. Journal of the American Academy of Child and Adolescent Psychiatry, 51(4), 368-383.

Mehzabin, P., \& Stokes, M. A. (2011). Self-assessed sexuality in young adults with high-functioning autism. Research in Autism Spectrum Disorders, 5(1), 614-621.

Miletski, H. (2002). Understanding bestiality-zoophilia. Bethesda, MD: Author.

Milton, J., Duggan, C., Latham, A., Egan, V., \& Tantam, D. (2002). Case history of co-morbid Asperger's syndrome and paraphilic behaviour. Medicine, Science and the Law, 42(3), 237-244.

Moher, D., Liberati, A., Tetzlaff, J., \& Altman, D. G. (2009). Preferred reporting items for systematic reviews and meta-analyses: the PRISMA statement. Annals of Internal Medicine, 151(4), 264-269.

Moser, C. (2009). When is an unusual sexual interest a mental disorder?. Archives of Sexual Behavior, $38(3), 323-325$.

Nichols, S., \& Blakeley-Smith, A. (2009). "I'm not sure we're ready for this...”: Working with families toward facilitating healthy sexuality for individuals with autism spectrum disorders. Social Work in Mental Health, 8(1), 72-91.

Parchomiuk, M. (2018). Sexuality of Persons with Autistic Spectrum Disorders (ASD). Sexuality and Disability, 1-16.

Ranger, R., \& Fedoroff, P. (2014). Commentary: Zoophilia and the law. Journal of the American Academy of Psychiatry and the Law, 42(4), 421-426.

Raymond, N. C., Coleman, E., Ohlerking, F., Christenson, G. A., \& Miner, M. (1999). Psychiatric comorbidity in pedophilic sex offenders. American Journal of Psychiatry, 156(5), 786-788.

Ruble, L. A., \& Dalrymple, N. J. (1993). Social/sexual awareness of persons with autism: A parental perspective. Archives of Sexual Behavior, 22(3), 229-240. 
Schöttle, D., Briken, P., Tüscher, O., \& Turner, D. (2017). Sexuality in autism: hypersexual and paraphilic behavior in women and men with high-functioning autism spectrum disorder. Dialogues in Clinical Neuroscience, 19(4), 381.

Shaffer, L., \& Penn, J. (2006). A comprehensive paraphilia classification system. Sex crimes and paraphilia. New Jersey: Pearson Prentice Hall.

Silva, J. A., Leong, G. B., \& Ferrari, M. M. (2003). Paraphilic psychopathology in a case of autism spectrum disorder. American Journal of Forensic Psychiatry, 24(3), 5-20.

Singh, P. G., \& Coffey, D. B. J. (2012). Sexual obsessions, compulsions, suicidality and homicidality in an adolescent diagnosed with bipolar disorder not otherwise specified, obsessive-compulsive disorder, pervasive developmental disorder not otherwise specified, and mild mental retardation. Journal of Child and Adolescent Psychopharmacology, 22(3), 250-253.

Stokes, M., Newton, N., \& Kaur, A. (2007). Stalking, and social and romantic functioning among adolescents and adults with autism spectrum disorder. Journal of Autism and Developmental Disorders, 37(10), 1969-1986.

Sullivan, A., \& Caterino, L. C. (2008). Addressing the sexuality and sex education of individuals with autism spectrum disorders. Education and Treatment of Children, 381-394.

Swedo, S. E., Baird, G., Cook, E. H., Happé, F. G., Harris, J. C., Kaufmann, W. E., ... \& Spence, S. J. (2012). Commentary from the DSM-5 workgroup on neurodevelopmental disorders. Journal of the American Academy of Child and Adolescent Psychiatry, 51(4), 347-349.

Szatmari, P., Chawarska, K., Dawson, G., Georgiades, S., Landa, R., Lord, C., ... \& Halladay, A. (2016). Prospective longitudinal studies of infant siblings of children with autism: lessons learned and future directions. Journal of the American Academy of Child and Adolescent Psychiatry, 55(3), 179187.

Travers, J., \& Tincani, M. (2010). Sexuality education for individuals with autism spectrum disorders: Critical issues and decision making guidelines. Education and Training in Autism and Developmental Disabilities, 284-293. 
Volkmar, F. R., Szatmari, P., \& Sparrow, S. S. (1993). Sex differences in pervasive developmental disorders. Journal of Autism and Developmental Disorders, 23(4), 579-591.

Werling, D. M., Parikshak, N. N., \& Geschwind, D. H. (2016). Gene expression in human brain implicates sexually dimorphic pathways in autism spectrum disorders. Nature Communications, 7 , 10717.

Wing, L. (1981). Asperger's syndrome: a clinical account. Psychological Medicine, 11(1), 115-129.

Yakeley, J., \& Wood, H. (2014). Paraphilias and paraphilic disorders: diagnosis, assessment and management. Advances in Psychiatric Treatment, 20(3), 202-213. 


\section{Figure 1. PRISMA Flow Diagram}
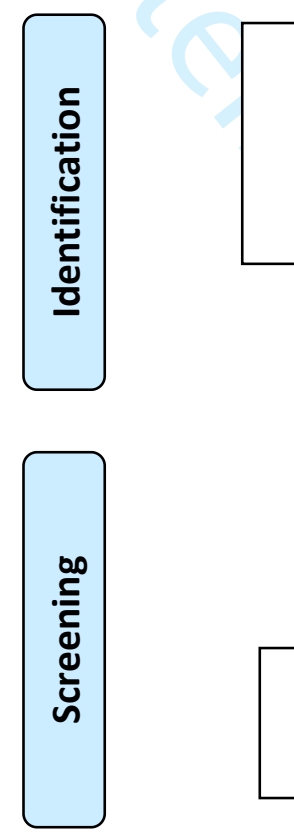

Records identified through database searches

2
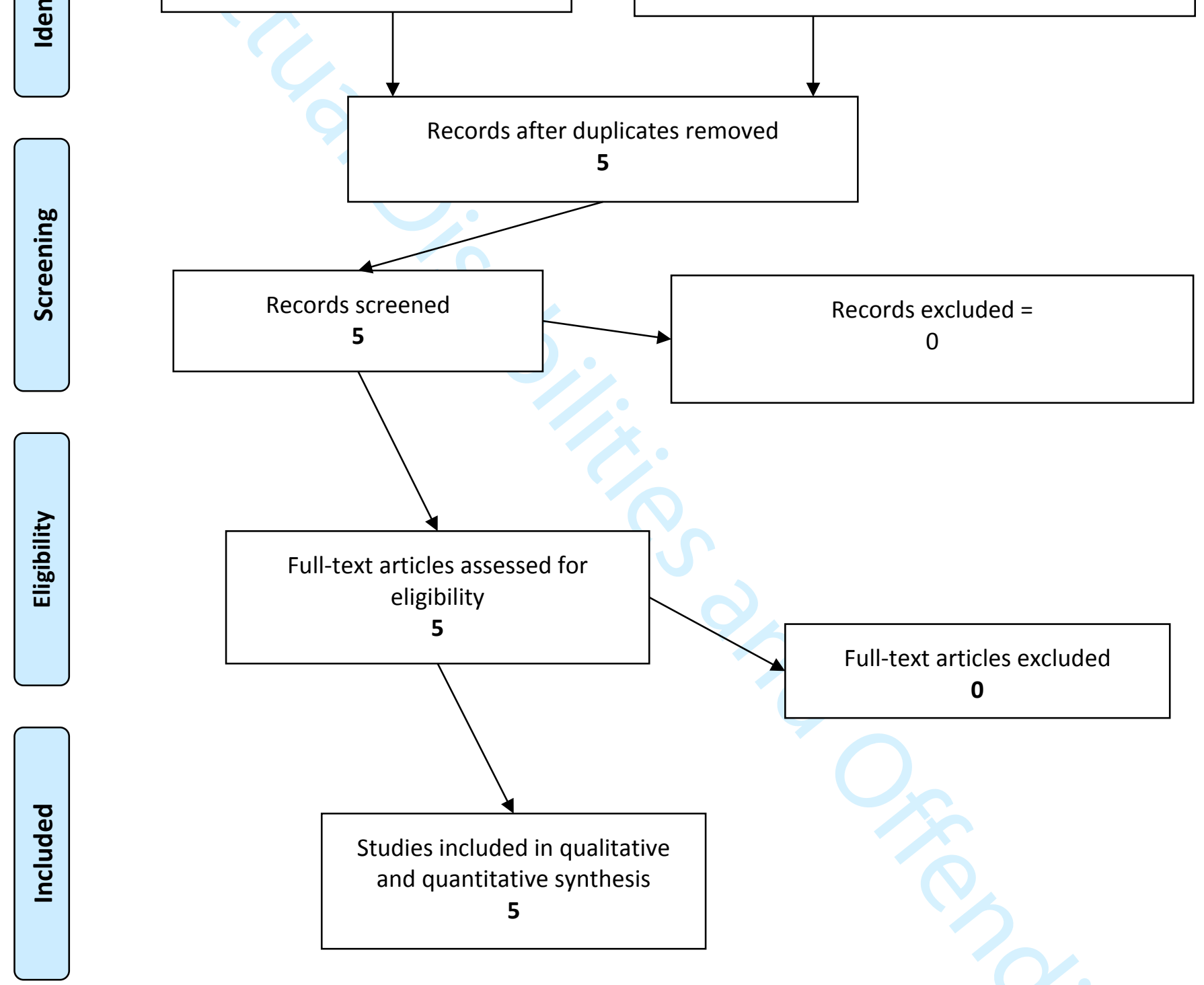

Additional records identified through other sources

\section{4}

\section{Full-text articles excluded}

0

Studies included in qualitative and quantitative synthesis 5

From: Moher D, Liberati A, Tetzlaff J, Altman DG, The PRISMA Group (2009). Preferred Reporting Items for Systematic Reviews and MetaAnalyses: The PRISMA Statement. PLoS Med 6(7): e1000097. doi:10.1371/journal.pmed1000097 